\title{
Brief Research on City Identity Crisis and Causes of Small/Medium-Sized Cities in China
}

\author{
Qianyao Huang ${ }^{1}$ \\ ${ }^{1}$ The University of Edinburgh, Edinburgh, UK \\ Correspondence: Qianyao Huang, The University of Edinburgh, Edinburgh, UK.
}

Received: June 30, 2019

doi:10.20849/ajsss.v4i3.635
Accepted: September 23, $2019 \quad$ Online Published: September 24, 2019

URL: https://doi.org/10.20849/ajsss.v4i3.635

\begin{abstract}
City identity can be defined as the soul of a city and it plays an important role in increasing urban competitiveness (Gao, 2010). Recently, urban distinct features including historic heritages have been badly damaged in the rapid process of urbanization and economic growth, generating a crisis of city identity loss in urban planning, especially in small/medium cities where many have become similar in recent decades. The issue of a crisis in city identity has become established globally. With recognition of identity value, and the rising of people's physical, as well as, psychological living demands in seeking a sense of belonging, extensive attention has been given to protection of city characteristics and identity recovery by both policy makers and urban designers ( $\mathrm{Li}$ and Wang, 2006).

Particularly, in China, rapid urbanization as a result of economic growth has led to city identity becoming reduced ( $\mathrm{Li}, 2005)$. Homogenization and standardization in urban planning is very common and prominent in small/medium size cities in China. Many cities face a crisis where historic character and original identity is disappearing gradually and inevitably (Akkar Ercan, 2016).

The principle aim of this paper is to discuss what is urban identity crisis and to explore it causes. In targeting this proposal, the following 2 questions and issues may need to be taken into consideration: 1 . What is the definition and composition of the City identity? 2. What is the city identity crisis, including its causes and consequences? This requires systematic research on both literature review and world-wide case studies to explore the the city identity crisis and this may provide comprehensive, instructive, and operational design guide for shaping a 'visible' city's identity, enhancing its uniqueness and further contributing to the solution for city identity crisis in China.
\end{abstract}

Keywords: city identity, city identity crisis, urban design, China

\section{Introduction}

Against the background of growing globalization, according to Table 1, in the past three decades, since China adopted reforms and the opening-up policy (Note 1), the level of urbanization area has grown to more than 50\% from less than $20 \%$ prior to the reforms and opening up. On the one hand, individuals are enjoying the improvement of materials brought by rapid urban economic development. On the other hand, the city's identity has been gradually swallowed by the tide of rapid urbanization. Mr. Jin Jinyuan once remarked that a city is a structure of various materials including concrete, asphalt and glass which is not connected with a natural environment and even if modern materials and techniques are used to build structures, such a city cannot absorb modern thinking and associated cultural insight (Jin, 1990). In History and Truth, French philosopher Paul Ricoeur noted the inherent discrepancies within globalization as not every culture can 'absorb the impact of modern civilization' and issues remain as to how modernization can exist alongside pre-existing cultures (Ricoeur, 2007). The loss of urban features has become an indisputable fact within academic discussion and many experts have resolutely stated that urban economic development should not occur at the cost of reducing urban characteristics and the loss of city identity. In the last decade, experts and scholars in China have been pursuing methods to be used in protecting urban identity, conducting research and implementing their ideas. However, such research has not completely achieved its aims although some results have been achieved.

According to the rising trend shown on the table 1, urbanization in China at present is still in the high-speed growth stage and it is predicted that this will continue for the next 20 30 years. According to the related research, China's urbanization will not truly achieve a stable stage until 2030 2040, when the level of urbanization in China is 
predicted to have reached $70 \% \sim 80 \%$ bringing a relatively stable level ( $\mathrm{Wu}$ and $\mathrm{Li}, 2010$ ). In such stages of development, on one hand, self-reflection is necessary to analyze the regularity of the evolution of city identity in the history of China, and horizontally compare and study the evolution of characteristics in western city identities alongside summarizing causes of the loss of city identity based on decades of urban planning in China.

Table 1. The level of urbanization in China

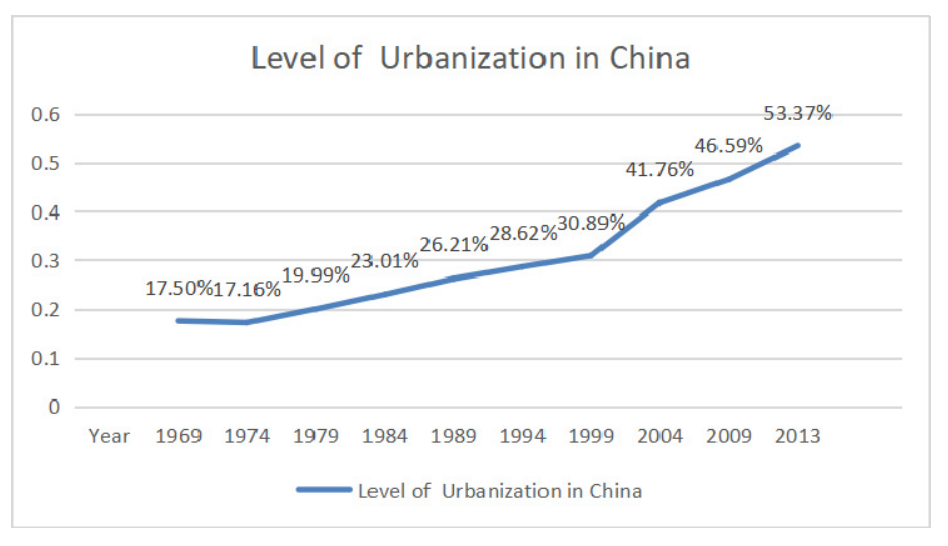

\section{Conceptualising City Identity}

City identity can be recognised through inclusion of the social value and cultural connotations of a city's characteristics, and its property including the uniqueness, hierarchy, scale, cohesiveness, and variability in time and space (Baris, 2014) and city identity also refers to the place identity in an urban environment (Ujang and Zakariya, 2015). The author prefer to consider identity of a city is more subjective, as Relph pointed out that the identity of a place depends in some degree on the observer themselves, as it is the experience of the eye, the mind, and the intention of the observer about the physical appearance of the place (Relph, 1976). Kevin Lynch stated in the book The Image of the City that city identity provides a place's individuality or distinction from other places and serves as the basis for its recognition as a separate entity (Lynch, 1960).

Comprehensively, the composition of city identity is a complex interaction of 3 different components: 1 . The physical setting or appearance; 2. The function or observable activity; 3 . The meaning and symbols. It is a collection of distinctive urban features, which includes the historical traditions, the geographical location, the natural resources, the architectural form, the diet culture, the customs, etc. All of these can constitute a unique city identity.

\section{City Identity Crisis and Its Causes}

The crisis of city identity is mainly reflected in the weakening of the original identity and the difficulty in adapting to the new identity. The former is mainly found in the destruction of historical sites and the damage of natural landscape features. The latter is often embodied in the emergence of a large number of standardized buildings and landscapes in a short time, resulting in the convergence of cityscapes. Such imbalance has created a crisis in today's city identity.

\subsection{Critical Analysis of City Identity Crisis in China}

\subsubsection{The Crisis of Historical and Cultural Heritage}

In rapid urbanization in China, the old city renewal is of great importance in urban development. Apart from the key cultural relics, many historic and cultural buildings have been demolished. For instance, the old city walls and Siheyuan in Beijing are disappearing; no more water flow into the river ways in Suzhou; and the Qilou streets in Guangzhou have been gradually removed, etc. At the same time, as a symbol of modernization, high-rise buildings or buildings that are not in harmony with historical features have begun to replace the original historical district, severely damaging the texture of historical sites.

In spite of the overall trend, several cities in China continuously focus on the protection and restoration of historical traditions, such as Xi'an. Owing to years of persistence, the urban construction is highly related to the historical origins. Admittedly, it was criticized for the 'fake antique' in urban designs at the beginning. However, the construction of other cities is not archaized enough to become a new symbol of the city. Hence, the efforts of 
Xi'an are believed to be valuable ( $\mathrm{Lu}, 2010)$. In addition, there were some architectures featuring a combination of Chinese and Western styles in Lingnan Area during the period of the Republic of China, such as the educationfunctional buildings in Sun Yat-sen University, an innovation based on traditional Chinese architecture with high identity.

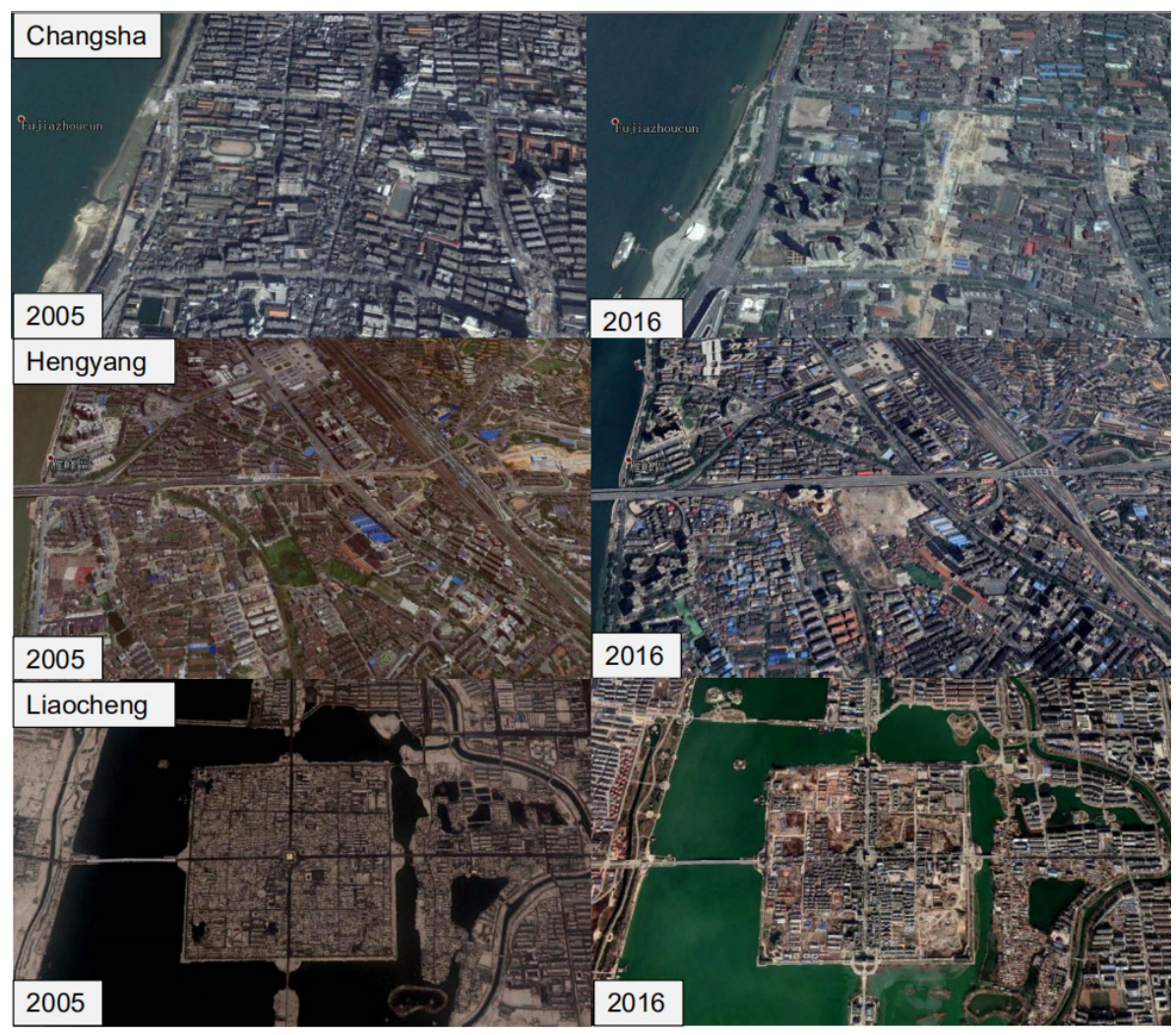

Figure 1. Changes of the old city district of some cities in China from 2005-2016

Resources: Google Earth

\subsubsection{The Crisis of Cities Homogeneity}

With the arrival of modern civilization, the human achieves great leaps in the ability of remodelling. At the same time, there is an increasingly stronger demand for self-realization, leading up to the comparison between cities. However, in the disguise of human vanity, modernization is always used to measure the competitiveness of the city, so acting on 'international convention' has become the consensus of many cities in China. To be specific, small and medium-sized cities imitate big cities, while big cities copy western cities. Abstract 'modernization' goals have formed the prosperity of specific standards under the urgent demand of rapid economic development. Many cities in China take the high-rise buildings as the totem, the expressways as the skeleton, and the development of new districts as the growth pole, so as to put the spatial production into practice (Wu, 2010). It is embodied in the homogeneity of architectural style and planning pattern.

\subsubsection{Homogeneity of Architectural Style}

Within the context of the market economy system, Chinese cities, especially medium-sized cities, began to pursue diversified development in the style and form of architecture. However, instead of basing on local history, culture, or natural environment, such diversification is more as a popular commercial symbol, which is always applied as a pretext for internationalization. In fact, it is mainly to cater for the public tastes of different periods, so as to pursue more benefits, which is represented by the popularity of 'XX Style'; 'European style', 'Mediterranean style' and so on. However, things suddenly occurred and popularized cannot stand the test of time. Taking the 'XX style' for example, it was popular once, but it just became a formal label rather than an identity. In addition, as time goes by and the public aesthetics changes, these 'XX styles' will inevitably be abandoned by time, even though they have 
aroused great enthusiasm in the market. City designers and planners have begun to cautiously handle the prevalence of 'XX style' in the market. Nevertheless, due to the rapid urbanization process in the past, they have existed in the urban space in large amounts. Consequently, the regional and traditional culture has become subsidiary factors in urban design (Yu, 2007).

\subsubsection{Homogeneity of Planning Pattern}

It is mainly embodied in the construction of CBD, industrial park, development zone, as well as the popularity of large squares and landscapes. In construction, the experience of other cities was copied blindly, resulting in the generation of low-level repetitive construction. To a certain extent, it produces the homogeneity of cityscapes. As Mr. Andreas Gottlieb Hempel, the president of German Architectural Association, commented when he came to visit Beijing in 2015, 'nowadays, if I drive my car toward the central part of Beijing city from outskirt, I will never know where I am. I can be in Miami, or in Singapore, also can be in Franklin because all the high-rise buildings are same and have a few of their own special individuality. Only from the Chinese characters around me can I tell that I am in China. This is not a good thing for Chinese future'.

\subsection{Causes of City Identity Crisis}

\subsubsection{From the Perspective of History: Interruption of Historical Traditions}

From the above analysis of city characteristics and identity of both Chinese and Western cities, we can see that the destruction of the city identity today is mainly due to the historical reasons, while our ancestors lacking consciousness in protection of historical traditions, which including both physical and mental heritages. The author finds that there is a big difference between Chinese and Western attitudes towards the historical culture, and the relationship between urban construction and heritages is roughly shown in the Table 2 and 3.

Tables $2 \& 3$. Relationship between urban construction and heritages of China and western countries
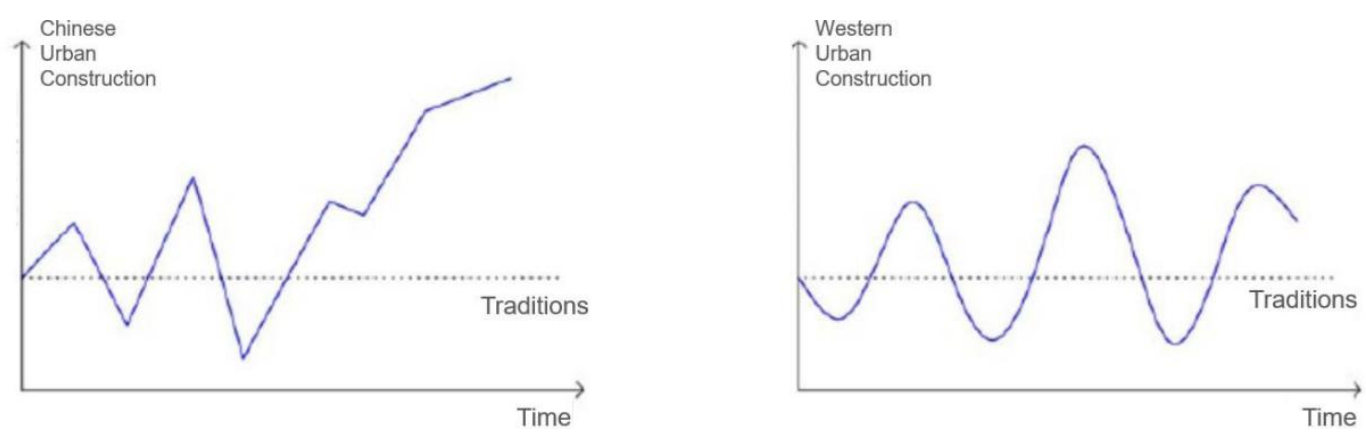

In detail, for Chinese cities, Chinese cities have basically maintained the traditional context before the First Opium War (Note 2). Although, every time when change the ruling class (emperor), there would be a large-scale of demolition and reconstruction for building new orders, however, this construction mainly focused on the architectures and the city pattern would still be maintained due to the impact of Confucian theories (Wu, 2008). But after the First Opium War, we were increasingly deviated from our own traditions, as during this period, China was seriously suffered the invasion of Western powers. At that time, Chinese people were very unsure about the traditions and cultures, and were always felt that anything of the West was good, hence, the invasion of military also brings the invasion of policy and culture. Moreover, when comes to the 19th century, the ancient wooden structure buildings were no longer suitable for people's increasingly demand of the life, so there was a tendency to depart from the tradition (move out form the old buildings or even demolish and rebuild at the original site), which leading a large scale of heritage decline and damage. As Cheng Taining said, 'Our architectural creation, to some extent, is dominated by post-colonial thoughts with a lack of Chinese cultures and spirits, which is one of the important reasons for the similarity of Chinese cities which a lack of identity' (Chen, 2015).

For Western cities, western cities established the foundation of the current western identity through the ancient Greek-ancient Rome-the Middle Ages-Renaissance and it reached the acme during the Renaissance period. The later development has not lost the traditional context, and the protection of historical sites has also been accompanied by the process of urban development (except for a small number of authoritarian updates) (Gospodini, 2004). Just as every building was carved as exquisite artworks during Renaissance, city planners and designers in western cities have respected the history from master plan to single building's construction. Reconstructed and 
updated works also adhere to 'principles of successors', which is to cherish and cautiously treat the heritage from predecessors and balance the ole and the new in the city, to achieving a harmony of the whole city (Li, 2012), for instance, many cities like Edinburgh which mainly in the World Heritage Area have established abundant related planning policies to strictly control the new construction on the historical sites.

Chinese famous architect Wang Shu comments on tradition interruption in China: 'For the interruption of traditions, I think there are several stages. Tradition is carried on by the people, and inherited in the way of daily life. As for ancient Chinese traditions, besides the royal family in the Forbidden City, there were scholars, farmers and traders. Firstly, is the destruction of scholars' traditions as the ideological transmission is basically interrupted through cultural invasion. Secondly, is the destroy of the old things. In a shocking erroneous movement of Destroying the Four Olds' (Note 3) in Modern China, a large number of historical relics were destroyed and valued ones are exported via Hong Kong in 1970s for getting the foreign exchange for the country. Thirdly, is the demolition of the old buildings. Historical buildings have been removed by an astonishing number (almost $90 \%$ ) in the past fifty years, which makes China as a 'capital of demolishment'. In first stage, there was no traditional thoughts from the last generation, and then there was no old things, and finally even the old houses were emptied' (Wang, 2015). That is why it is important for China to remain and protect even a damaged and useless historic building in the city nowadays as there is really not much left, and the cultural identity of the place would astonishing be completely gone if there was nothing historical left. Zhu Tao, a Professor of Architecture in University of Hong Kong, illustrated the reasons for the interruption of historical traditions: 'There are at least three categories, one is the large-scale of demolition and reconstruction due to the changes of dynasties, and one is the guideline of 'no making without breaking' in modern radical revolution during modern China, and the last is that the modernist elites, transformed into the so-called international designers and planners under the impetus of globalization, who feel freely to land the buildings which are completely separated from the local cultural context in Chinese city, these three activities treat Chinese city like a blank sheet of paper and doodle freely to make China what it is today' (Zhang,2015).

Additionally, the traditional consciousness and protection consciousness of Chines people are far less than that of the West. For example, many Europeans cherish the old things in their houses, and it is a tradition that keeps many buildings for hundreds of years with a relatively sound system of management and protection. However, what is frustrating is that too much heritage to protect and renewal would also cause the pressures of economic and public opinions, for instance, when 'Edinburgh 12' developments launched, there are lots of arguments (Skyscrapercity.com, 2017). Therefore, for China, the medium-term strategies should focus on heritage protection and restoration for recovering city identity, and for a longer planning, it is recommended to seek a relatively balance between the old and the new, especially under the force of economic growth in medium cities of China.

\subsubsection{From the Perspective of Economic Development Background-Particularity of Rapid Urbanization in China}

Generally, unique urban spatial characteristics and pattern of historic cities are gradually formed through a long-term development and accumulation. However, after entering the rapid urbanization, urban sprawl in Chinese city gets rid of the natural growth. The short-term accumulation of various cultures is difficult to catch up with the high-speed and large-scale of urban construction, for example, a large number of 'xx Style' structures built while people cannot gradually accept them as a unique urban identity but just as a symbol of popularity, which will inevitably lead to the elimination of original urban features. The particularity of this kind of rapid urbanization is embodied in: firstly, different from the western countries, majority of them are in the mature stage of urbanization at present, which means the level of urbanization is relatively stable, China's current urban development is still take the economic growth as the first essence for enhancing China's position in the world, which is unavoidably leading to a high speed of urban construction. Secondly, the rapid growth of urban population also results in a large amount of city construction, including the renewal of old cities and extension of new districts (Zhuang, 2004).

For most cities, they have not yet reached the stage of pursuing the refinement of every building due to the large demands and limited budget, and the only way to solve the huge increments of construction is through standardization of urban designs, thus, there is a homogenization phenomenon of construction in some parts of the city. Thirdly, many western urban design concepts have been introduced through the globalization, which is very popular in China, and it is worried that whether it will be the threat of original city identity.

Therefore, in the process of rapid urbanization, for many cities in China, the economic developed, the old lifestyle changed, the industrial market constantly adjusted, new urban design concepts imported, and the urban space has been gradually remodelled. For this situation in China, Shi Nan, secretary of China Urban Planning Society, commented, 'the most serious damage to the heritage, may not the dynastic changes, or even war, but the rapid growth economic'. In this case, the city identity is difficult to stabilize. However, as a matter of fact, it is 
unavoidable, in the rapid urbanization stage of western cities, there are also a crisis of heritages, for instance, in the rapid expansion period of Macedonia and ancient Roman, there were also homogenization phenomenon of similarity of cityscapes (Csaszar, 2009). Thus, it is advised to seek a long-term solution and learn from the experienced countries for tackling the identity crisis.

From the perspective of economic budget - especially frustrated in the medium city of China It may be somewhat frustrated to talk about the crisis of city identity in China from the perspective of economy, especially for medium cities and Hengyang city which for comprehensive case study is in this situation. Firstly, the old residential houses in China dating back to ancient times are mostly low-rise wooden or brick-mud houses, such as Siheyuan (a historical type of residence) in Beijing (figure 2), only the wall of inner-city and imperial architecture are in exquisite structures $(\mathrm{Lu}, 2010)$. Besides, good quality construction is generally in the capital city of ancient China, namely, big cities at present. The standard of common residential construction in medium cities are even lower and easier damaged by worms, corrosion, fire and other erosion. Unlike the ancient buildings in European cities, they are mostly made from concrete or stones, and are quite solid. Moreover, the infrastructure of these old houses is far from meeting the needs of modern people's life, as the wooden and brick-mud structure are difficult to install the modern water and electricity systems. Secondly, if we want to protect and renewal the heritage, it will create expensive economic costs to refurbished the infrastructure in the historic site, to repair and maintain the building's structure.

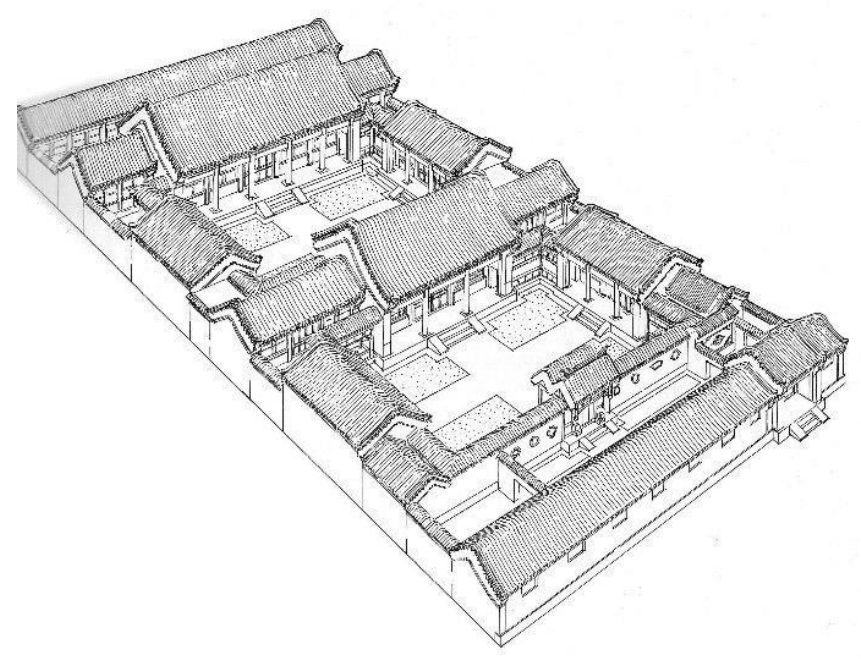

Figure 2. General structure of Siheyuan in Beijing

Resource: https://huaban.com/pins/1479145710/

That is to say, if the government does not have a strong financial support, the protection and restoration of heritage can only be an armchair strategy. Especially in the medium/small city of China, as there are numerous cities in China, medium-size city means there is a certain level of urban resources as well as a medium economic background, which may have but limited budget for specific projects for heritage protection and city identity building. Therefore, what we can do under limited budget, is to collect the essence of traditional culture and to find the potential and value of the heritage, seeking a strategic planning approach, transforming the traditions to valuable city identity resources.

\section{Conclusion}

In the context of rapid urbanization and economic development, many cities in China are facing the crisis of urban identity, as well as the phenomenon of city homogenization. This paper aims to critically analysis this problem, including the theoretical discussion of urban identity, in-depth analyses of the city identity crisis and its causes. Conclusions are drawn as follows:

1. In general, city identity refers to the place identity in an urban environment, and the attributes of the city identity are usually artistic, holistic periodical and subjective.

2. City identity crisis worldwide can be seen from the crisis of historical and cultural characteristics, the crisis 
of natural resources and city homogenization. The loss of city identity may caused by the interruption of historical traditions, the dominance of rapid urbanization, the decline of economy in reality.

Overall, the crisis of city identity in China is a complex systematic process, which involves a very wide range of area, involving the historical events, economic background and some other aspects that this paper not detailed discussed, for instance the lack of systematic study of city identity made by the designers and planners, or the aesthetic blindness of residents. Therefore, due to the limit in the author's ability and time, this study also has some shortcomings. Of course, the essence of urban planning is to continually discuss the past, criticize the current and to establish an ideal mode of the future. It is this ideal that inspires urban research and urban planning to develop continuously, and during the process of urban development, our understanding of city identity is also deepened.

\section{References}

Akkar Ercan, M. (2016). 'Evolving' or 'lost' identity of a historic public space? The tale of Gençlik Park in Ankara. Journal of Urban Design, 1-24.

Baris, M., Uckac, L., \& Uslu, A. (2014). Exploring public perception of urban identity: The case of Ankara, Turkey. African Journal of Agricultural Research, 4(8), 24-735.

Chen, H. (2015). The Urban Planning of Modern China. Retrieved 10 July 2017, from https://max.book118.com/html/2014/0927/9734568.shtm

Csaszar, T. (2009). Waldemar Heckel, the Conquests of Alexander the Great. Past Imperfect, 15.

Engardio, P. (2005). China Is a Private-Sector Economy. Bloomberg Business Week, (8).

Gao, B. (2010). Comprehensive Urban Design in Small Cities for Creation of Features. The University of Tianjing.

Gospodini A. (2004). Urban Morphology and Place Identity in European Cities: Built Heritage and Innovative Design. J. Urban Design, 9, 225-248.

Jin, J. (1990). The Regularity of Urban Characteristics and the Initiative of Planning. Urban Planning, (5).

Li, G., \& Wang, Y. (2006). Urban Identity and Urban Image Con-Struction. City Planning Review, 2.

Li, S. (2005). Localization of Urban Design. Beijing: China Architecture and Building Press.

Li, X. (2012). The Application and Research of "Slow Design" in Rapid Urbanization. Chan'an University.

Lu, L. (2010). Avoiding the 'Cities Similarity' Phenomenon through Historical City Protection. Urban Planners, 1.

Lynch, K. (1960). The image of the city. Cambridge, Massachusetts: The MIT.

Palmer, J. (2007). Urban Future. The International Journal of Environmental, Cultural, Economic, and Social Sustainability: Annual Review, 2(1), 123-128.

Relph, E. (1976). Place and placelessness. London: Sage.

Ricoeur, P. (2007). History and truth. Evanston, Ill: Northwestern University Press.

Skyscrapercity.com. (2017). The Edinburgh 12 - Skyscraper City. Retrieved 4 August 2017, from http://www.skyscrapercity.com/showthread.php?t=1741874

Ujang, N., \& Zakariya, K. (2015). The Notion of Place, Place Meaning and Identity in Urban Regeneration. Procedia - Social and Behavioral Sciences, 170, 709-717.

Wu, G. (2008). Urban Identity - A Hard but Heavy Topic. Urban Characteristic Planning, 10.

$\mathrm{Wu}$, S. (2015). A Study on the Inheritance and Development of City Landscape under the Background of Urbanization. Master. Guilin University of Technology.

Wu, Z., \& Li, D. (2010). Principles of Urban Planning (1st ed.). China Construction Industry Press.

Yu, B. (2007). Urban Characteristic Aesthetic Structure and Its Instability. Urban Planning, 1(167), 111-115.

Zhang, H. (2015). The systematization of Cityscape and City Characteristics. Environment Art, 05.

Zhuang, Y. (2004). The Operation of Urban Design. Shanghai: Tongji University Press.

\section{Notes}

Note 1. The Chinese economic reform, started in December 1978, was launched by reformists within the Communist Party of China, led by Deng Xiaoping. It refers to the program of economic reforms termed 'Socialism with Chinese characteristics' in the People's Republic of China. (Engardio, 2005). The success and 
implementation of China's economic policy led to the great changes in Chinese society. Large-scale government planning programs, together with market characteristics, significantly reduce poverty, while the income disparities increased.

Note 2. The First Opium War, also known as the Opium War or the Anglo-Chinese War, was a series of military engagements fought between the United Kingdom and the Qing dynasty over conflicting viewpoints on diplomatic relations, trade, and the administration of justice in China.

Note 3. The Four Olds referred to Old Customs, Old Culture, Old Habits, and Old Ideas. One of the stated goals of the Cultural Revolution in the People's Republic of China was to bring an end to the Four Olds. This campaign is the movement began in Beijing on August 19, 1966, shortly after the launch of the Cultural Revolution.

\section{Copyrights}

Copyright for this article is retained by the author(s), with first publication rights granted to the journal.

This is an open-access article distributed under the terms and conditions of the Creative Commons Attribution license (http://creativecommons.org/licenses/by/4.0/). 